\section{Imperialismo e dependência versus interdependência: o lado silenciado de um embate teórico}

\section{Imperialism and Dependence versus Interdependence: the muted side of a theoretical clash}

DOI: 10.5752/P.2317-773X.2017v5.n3.p35

Rejane Carolina Hoeveler ${ }^{1}$

Recebido em: 01 de junho de 2017. Aceito em: 15 de novembro de 2017.

\begin{abstract}
RESUMo
O artigo desenvolve uma contraposição entre a teoria da dependência, em suas diversas variantes, e a teoria da interdependência, tal como elaborada por Joseph Nye e Robert Keohane, no contexto histórico internacional dos anos 1970. Objetiva, a partir de uma crítica marxista, demonstrar que a teoria da interdependência emerge no mesmo momento histórico no qual espraiam-se pelo mundo as teorias da dependência e do imperialismo, analisando de que modo a constituição teórica do conceito de "interdependência complexa" invalida os pressupostos centrais de qualquer teoria da dependência. Trata também da atuação política de Nye e Keohane como intelectuais orgânicos, a partir de sua ativa participação em aparelhos privados de hegemonia como o Council on Foreign Relations (CFR) e a Trilateral Commission - a partir dos quais seus conceitos irradiaram-se em organismos internacionais como o Banco Mundial. Metodologicamente, o artigo procura cruzar a contextualização histórica das teorias da dependência e da interdependência com uma análise interna das mesmas.
\end{abstract}

Palavras-chave: Teoria da dependência; interdependência complexa; Joseph Nye; Robert Keohane; Imperialismo

\section{ABSTRACT}

The article develops a contraposition between the theory of dependency in its various variants and the theory of interdependence, as elaborated by Joseph Nye and Robert Keohane, in the international historical context of the 1970s. It's objective, based on a critique Marxist theory, is to demonstrate that the theory of interdependence emerges at the same historical moment in which theories of dependence and imperialism spread around the world, analyzing how the theoretical constitution of the concept of "complex interdependence" invalidates the central assumptions of any theory of dependency. It also deals with the political acting of Nye and Keohane as organic intellectuals, from their active participation in private hegemonic apparatuses such as the Council on Foreign Relations (CFR) and the Trilateral Commission - from which their concepts have radiated in international organizations such as The World Bank. Methodologically, the article seeks to cross the historical contextualization of theories of dependence and interdependence with an internal analysis of them.

Key-words: Dependency Theory; complex interdependence; Joseph Nye; Robert Keohane; Imperialism
1. Doutoranda em História na Universidade Federal Fluminense (UFF), bolsista CNPq. ORCID: https://orcid. org/0000-0003-4299-5483. 
Introduçãa

"para os países em desenvolvimento mais fracos, a interdependência aparece como um sistema de dependência. Daí o apelo de teorias que enfatizam elementos de dependência na economia mundial, incluindo as corporações multinacionais, e as quais formam a base para grande parte da retórica, senão da estratégia política, de muitos países em desenvolvimento" (COOPER et all, 1977, p.191).

O termo "interdependência complexa", surgido no início dos anos 1970, é provavelmente um dos mais corriqueiros na disciplina de Relações Internacionais (R.I.) em todo o mundo. Embora algumas das idéias que embasaram sua difusão tenham sido revistas por seus próprios autores, Joseph Nye e Robert Keohane, ele segue compondo um arcabouço teórico respeitado e lido na área, ao contrário do que ocorre com as teorias da dependência e do imperialismo elaboradas nos anos 1960 e 1970.

Esse artigo tem como objetivo compreender a teoria da interdependência a partir de uma contextualização histórica de sua produção, mas também de uma análise interna de seus argumentos, vistos como um desenvolvimento da teoria funcionalista e liberal dentro das R.I., contrastando-a com a teoria da dependência em suas diversas matrizes, a partir da visão da Teoria Marxista da Dependência (TMD).

Nosso objetivo é demonstrar que, ainda que os autores da interdependência não tivessem como alvo central os teóricos da dependência (ao menos não explicitamente), e sim os autores da tradição "realista" nas Relações Internacionais, tal teoria constitui uma invalidação das teorias da dependência, em suas variantes marxistas e não-marxistas, em razão da alta influência de ambas nos movimentos sociais e nas propostas políticas "terceiro-mundistas" e anti-imperialistas de maneira geral, no contexto do início dos anos 1970.

Procuramos também demonstrar, a partir do arcabouço teórico gramsciano, que os propositores da chamada teoria da interdependência podem ser entendidos como intelectuais orgânicos, co-elaboradores de uma visão coletiva ligada a frações de classe organizadas em determinados aparelhos privados de hegemonia.

Na primeira parte do artigo, traremos um brevíssimo resumo sobre as teorias da dependência, para em seguida tratar da teoria da interdependência, inicialmente contextualizando-a na trajetória intelectual e política de Nye e Keohane, e posteriormente levantando os contrastes entre ambas teorias. $\mathrm{Na}$ quarta parte, sublinharemos algumas convergências e divergências entre o pensamento destes autores com Zbigniew Brzezinski, de forma a aclarar sua parceria política dentro de iniciativas como a Comissão Trilateral.

As teorias da dependência e o anti-imperialismo

Iniciada formalmente em 1948, no Chile, a CEPAL (Comissão Econômica para a América Latina) pretendia atender às especificidades econômicas e sociais da América Latina partindo inicialmente do paradigma da teoria do desenvolvimento, ou da modernização, cujo conceito de "subdesenvolvimento" equivalia basicamente a "ausência de indus- 
trialização". A recomendação dessa teoria era a de "modernização" das estruturas econômicas, sociais, institucionais e ideológicas, até atingir o chamado take off; quando país se tornaria capaz de um desenvolvimento auto-sustentado (LEWIS, 1955).

Embora não seja nosso objetivo aqui descrever a longa e complexa história da(s) teoria(s) da dependência em suas distintas matrizes, um breve resumo faz-se necessário, e o faremos com base na visão de Ruy Mauro Marini (1992), um dos principais teóricos da teoria marxista da dependência (TMD), e no trabalho mais recente de Adrián Sotelo Valencia (VALENCIA, 2005).

O projeto original da CEPAL, segundo Marini, inseria-se na tentativa por parte dos países "desenvolvidos" em dar uma resposta institucional e teórica às inquietações que se manifestavam nos países recém descolonizados e também na América Latina - inquietações acerca das desigualdades sociais internas desses países e também das desigualdades historicamente existentes nas relações econômicas e políticas internacionais (MARINI, 1992, p.67-74).

O impacto do Relatório Econômico da América Latina de 1949, publicado em 1950, foi considerável, e as obras do argentino Raul Prebisch, principal autor do relatório, mas também do brasileiro Aníbal Pinto e do mexicano Victor Urquidi - todos ocupantes de cargos nas sociedades políticas de seus países em algum momento - tornaram-se incontornáveis no debate latino-americano (GURRIERI, 1982).

Embora estivesse longe de uma teoria do imperialismo, a teoria cepalina introduziu uma crítica crucial às idéias liberais predominantes acerca do comércio internacional: no lugar das idéias derivadas das "vantagens comparativas" a la David Ricardo, a CEPAL procuraria demonstrar a existência de uma tendência à deterioração dos termos de troca, ficando sempre prejudicados os países exportadores de produtos primários. Por conseguinte, enfatizava a existência de uma transferência de renda que implica uma sangria de riquezas dos países "subdesenvolvidos" em direção aos países "desenvolvidos". A teoria da troca desigual afirmava explicitamente que o "subdesenvolvimento" da maior parte do mundo era condição necessária para o "desenvolvimento" dos países ricos (MARINI, 1992, p.75-77).

No início da década de 1960, a CEPAL modifica suas colocações inicialmente alinhadas com a teoria do desenvolvimento, dando mais ênfase às reformas estruturais. Em essência, tratou-se de uma inflexão motivada pelas crises econômicas que estouraram em países como o Brasil, que havia recebido investimentos externos substantivos e avançado na industrialização, deixando intocáveis, entretanto, a concentração da propriedade e a superexploração do trabalho. Segundo Marini, essa crise, geradora de espirais inflacionárias que abocanhavam ainda mais dos já minguados salários reais dos trabalhadores latino-americanos, contribuiu para um novo ciclo de lutas sociais, potencializado pela vitória da revolução cubana em 1959. Assim que começa a avalanche de golpes militares, o desenvolvimentismo cepalino teria entrado em crise, abrindo espaço para teorias que, embora tenham se gestado no pensamento cepalino, o criticavam (MARINI, 1992, p.80-85). 
2. Primeiro autor brasileiro a analisar criticamente a Comissão Trilateral e a política externa do governo Carter, em livro publicado em português em 1979 (ASSMAN et all, 1979).

3. Marini traria uma contribuição original de peso na TMD, com os conceitos de superexploração da força de trabalho e de "subimperialismo", no qual adiantava uma análise refinada acerca de um fenômeno que se ampliaria muito nas décadas seguintes: a exportação de capitais de origem brasileira, para outros países dependentes (MARINI, 2000; 2012 [1977]; 2012; e LUCE, 2011).
A chamada teoria da dependência aparece inicialmente em um conjunto de trabalhos publicados entre 1964 e 1967, em um processo extremamente rico de discussão latino-americana, contraditoriamente estimulado pelos exílios induzidos ou forçados pelos golpes militares. Mas esse debate reverberou nos Estados Unidos, como demonstra a crítica de André Gunder Frank a algumas teses de Celso Furtado. O argumento central de Gunder Frank era de que o desenvolvimento capitalista em países dependentes sempre implicaria em mais dependência, e não em independência (FURTADO, 1961; GUNDER FRANK, 1966). A obra de Celso Furtado já era conhecida em diversos países, inclusive nos Estados Unidos, bem como a de Fernando Henrique Cardoso e de Enzo Falleto, cuja obra mais importante foi escrita no Chile, entre 1964 e 1967 (CARDOSO \& FALETTO, 1977 [1967]).

Em síntese, a teoria da dependência, como explica Marini,

"levava a descartar a noção do desenvolvimento capitalista autônomo, cara aos ideólogos cepalinos, e a considerar que a dependência não poderia ser superada nos marcos do capitalismo" (MARINI, 1992, p.89)

Embora não se caracterizasse como uma teoria propriamente marxista, a teoria da dependência em suas versões mais difundidas afirmava que o imperialismo permeava toda a economia dependente, constituindo um elemento estruturante e determinante, embora não único e nem unívoco, do Estado e das relações sociais, políticas e culturais de maneira geral. Em todas as suas variantes, a preocupação subjacente à teoria da dependência era a consolidação, após a Segunda Guerra Mundial, de um sistema hegemônico cujo centro eram os Estados Unidos da América. Por sua vez, a teoria marxista da dependência (TMD) apresentou-se como uma atualização da teoria do imperialismo, sob as novas condições criadas no segundo pós-guerra - ainda que também inserissem a questão da dependência num painel histórico mais amplo. Os brasileiros Ruy Mauro Marini, Vânia Bambirra e Theotônio dos Santos ${ }^{2}$ pensaram a questão da especificidade das relações de dependência latino-americana propondo um horizonte de superação das condições de miserabilidade das massas populares nos marcos do socialismo. ${ }^{3}$

A renovação do debate marxista sobre imperialismo no mundo de língua inglesa também foi notável nos anos 1960. O economista Hugo Correa identifica nesse período três grupos de contribuições teóricas: além da teoria da dependência e, paralelamente, do pensamento "terceiro-mundista", destacaram-se os debates na revista Montlhy Review, puxados por Paul Sweezy, Paul Baran e Harry Magdoff; e também o pensamento trotskista, basicamente na figura de Ernest Mandel (CORREA, 2012, p.157).

E não era casual que o debate sobre o imperialismo ganhasse impulso no mundo anglo-saxão: a vaga de mobilização social em todo o mundo abriu o cenário para isso. Conforme o crítico literário Fredric Jameson, os anos 1960 começam com a revolução cubana e os primeiros sit-ins nos Estados Unidos em 1959, culminando em outro ápice em 1968, bastante forte em muitos países do chamado Terceiro Mundo (JAMESON, 1992; ALI, 2005). Além disso, o contexto histórico aberto ao final dos 1960 mar- 
ca uma renovação do alinhamento político internacional do chamado "Terceiro Mundo". ${ }^{4}$ No âmbito da esquerda, em 1966, havia sido criada, em Cuba, a aliança Tricontinental, organização de solidariedade entre os movimentos anti-coloniais/anti-imperialistas de países da América Latina, África e Ásia, no âmbito da qual o líder revolucionário Che Guevara pronunciou seu famoso discurso clamando "dois, três, muitos Vietnãs".

Em 1973, no bojo da escalada israelense no Oriente Médio, ocorre o embargo da venda de petróleo organizado pela OPEP (Organização dos Países Produtores de Petróleo), acompanhado ou precedido pela formação de uma série de organizações de produtores de minerais, como a Organização Internacional da Bauxita - movimentos descritos pelos intelectuais liberais como "antiquadas", "desestabilizantes", "nacionalistas" e "protecionistas" (BERGSTEN, 1974). Em seguida, a reivindicação por uma "Nova Ordem Econômica Internacional" nos fóruns multilaterais como a ONU ganha significativo peso internacional. ${ }^{5}$

Acrescente-se a isso uma crise de superprodução que começa a se manifestar já em finais dos anos 1960, levando a déficits comerciais crescentes nos países imperialistas centrais, principalmente nos Estados Unidos, e o acirramento do conflito inter-imperialista entre Estados Unidos, Alemanha Ocidental e Japão (BLOCK, 1977).

Nos Estados Unidos, o livro Age of Imperialism, de Harry Magdoff (1969), tornou-se best seller e deu bases mais sólidas a muitos manifestantes estadunidenses contrários às políticas imperialistas de seu país e solidários às reivindicações terceiro-mundistas (MAGDOFF, 1978). Como assinalou John Bellamy Foster, o trabalho de Magdoff atraiu consideráveis ataques por parte do establishment, ao mesmo tempo em que inspirou muitos dos que protestavam contra a guerra e contra a participação do país nas ditaduras militares latino-americanas (FOSTER 2002; GREEN, 2009). ${ }^{6}$ Outras obras críticas, ainda que não marxistas, como a de Sidney Lens, publicado originalmente em 1971, The forging of american empire, desmontavam o "mito da moralidade" das intervenções norte-americanas no mundo (LENS, 2006), obtendo considerável impacto político.

É na contramão desse movimento que intelectuais estadunidenses e europeus construirão teorias alternativas, implícita ou explicitamente contrárias à idéia de que o imperialismo fosse um traço central na análise das Relações Internacionais. É o caso da "interdependência" de Nye e Keohane, que embora tivesse como alvo central as idéias "realistas" em R.I., traziam em seu bojo uma negação das relações estruturais de dependência entre os países. Vejamos como esta teoria surgiu na trajetória intelectual desses dois importantes autores.

\section{O lugar da interdependência na trajetória intelectual de Nye e Keohane}

Joseph Nye, formado em Ciência Política pela Universidade de Harvard, torna-se professor da mesma em 1964, ocupando, posteriormente, vários cargos na prestigiada John F. Kennedy School of Government, da qual se tornaria diretor em 1995. Em suas primeiras publicações, ainda no início dos anos 1960, trabalhou com o conceito de "integração regional" e realizou alguns estudos de caso sobre o leste da África (Kênia, Uganda
4. Estamos utilizando o termo de maneira descritiva e não conceitual. Para uma crítica à chamada teoria dos três mundos, é incontornável a crítica de Ahmad (2002, p.170-176)

5. A “Nova Ordem Econômica Internacional" era um conjunto de propostas elaboradas no âmbito na Assembléia Geral das Nações Unidas ao longo de 1974, impulsionada por países do Terceiro Mundo com vistas a garantir melhores condições de negociação com os países centrais em diversas áreas como estabilidade no preço de matérias-primas, acesso aos mercados dos países desenvolvidos, transferência tecnológica, regulação de corporações transnacionais, entre outros.

6. De fato, o trabalho de Magdoff é o único, dos trabalhos marxistas, citado tanto por Nye e Keohane quanto por Brzezinski. 
e Tanganica - região que formaria a atual Tanzânia), e também sobre a América Central (NYE, 1965; NYE, 1968). Esses estudos incluíram o tema da formação de mercados comuns, os quais Nye analisou com um modelo explicitamente neo-funcionalista (NYE, 1970).

$\mathrm{O}$ autor funcionalista Ernest Haas seria uma grande referência para Nye e Keohane nos anos 1970. Em geral, os funcionalistas defendiam que uma melhor atuação das organizações internacionais implicava em "compartimentalizar" as questões, já que as organizações de caráter "técnico" ou específico funcionariam melhor do que as que tinham objetivos muito amplos e gerais, como seria o caso da própria Liga das Nações. Era a peace by pieces, no didático trocadilho anglófono.

A abordagem funcionalista introduziu a idéia de que a cooperação - preferível à competição, por ser mais eficiente na conquista desses benefícios - geraria um efeito gradual de "transbordamento", no qual o sucesso de determinada forma de cumprimento de um objetivo ou função passaria para as demais áreas (o famoso spill-over effect) - em um processo advindo da eficiência funcional, e não da politica (NOGUEIRA \& MESSARI, 2005, p.78). Uma das mais importantes contribuições de Haas a este pensamento foi a incorporação da dimensão política, ainda que no sentido estrito de decisão estatal, ao entendimento das instituições internacionais. Uma idéia chave em sua obra era a importância dos "valores" e do "aprendizado" das elites burocráticas e governamentais que compõem as instituições internacionais (NOGUEIRA \& MESSARI, 2005; HERZ, 1997).

A teoria da integração regional, tal como desenvolvida pelos funcionalistas, serviu como instrumental teórico para Nye em suas comparações entre diferentes processos de integração regional, como a Comunidade Econômica Européia e o Mercado Comum Centro-americano. Nesses estudos, o autor apresentou modelos explicativos sobre como os processos de integração expandiam-se de pequenas questões econômicas para grandes questões políticas e institucionais, fazendo uma distinção entre "micro-regiões econômicas" e "macro-regiões políticas". Não obstante a integração fosse tratada como algo essencialmente bom, o autor apontava também para suas "limitações" e "problemas". Nessa obra, Nye se alinhava explicitamente com a tradição "liberal" (de R.I.), entendendo a teoria da integração regional como intrinsecamente atrelada a ela (NYE, 1971).

Em 1972, o professor de Harvard organizou, com seu autor de referência, Ernest Haas, um livro sobre administração de conflitos através de organizações internacionais, obra que reuniu dados sobre 146 disputas em diferentes regiões do mundo que foram manejadas por organizações regionais ou internacionais no período entre 1945 e 1970 (NYE et all, 1972).

Por sua vez, Robert Keohane, também cientista político, e professor da Universidade de Princeton, era editor do prestigiado periódico International Organization (1974-1980) e membro do painel de Ciência Política da National Science Foundation. É importante notar que antes de seus trabalhos junto com Nye, Keohane estudou a formação de grupos de pressão de países pequenos na Assembléia Geral das Nações Unidas, fenômeno que a partir da década de 1960 passou a preocupar cada vez mais as potências imperialistas. (KEOHANE, 1967; 1969; 1971) Posteriormen- 
te Keohane viria a ocupar a presidência da prestigiada American Political Science Association, a APSA.

O primeiro trabalho de Nye e Keohane juntos foi Transnational Relations and World Politics, publicado inicialmente em formato de artigo na revista acadêmica International Organization (1971) e logo depois em forma de livro. Nesta obra, criticaram fortemente o que chamaram de paradigma "estadocêntrico", o qual, segundo eles, relegava um papel secundário às "interações intersocietais" (KEOHANE \& NYE, 1972), em forte diálogo com outros dois futuros membros da Trilateral Commission, Karl Kaiser e Richard N. Cooper - este último, um conhecido economista que, em um estudo encomendado pelo Council on Foreign Relations, utilizou a idéia de interdependência em suas análises de economia internacional, voltadas especialmente para questões monetárias e de investimento externo (COOPER, 1968).

Em Transnational Relations and World Politics, Nye e Keohane listavam os efeitos que a "multiplicação da interação transnacional e não-estatal", traziam: 1. "Mudanças de atitude dos cidadãos"; 2. "Pluralismo internacional" (a ligação entre grupos de interesse nacionais em estruturas transnacionais, freqüentemente envolvendo organizações transnacionais para sua coordenação); 3. Crescimento dos constrangimentos sobre os Estados; 4. Crescimento na habilidade de certos governos influenciarem outros; e 5. Emergência de atores autônomos, com "políticas externas privadas" que podem deliberadamente se opor ou colidir com as políticas estatais (KEOHANE \& NYE, 1971, p.337).

Segundo Stephen Gill, foi o escritor inglês Anthony Hartley, em um artigo na revista Interplay, o primeiro a lançar a idéia de "interdependência”. A revista Interplay foi fundada em 1967 pelo diplomata americano Gerard Smith (principal negociador americano no acordo de Salt I), e concebida como uma revista sobre relações Europa-Estados Unidos. Como mostra Gill, durante seu curto período de existência, até 1971, a revista publicou artigos de um largo espectro dentro do chamado "atlanticismo", e seria um modelo para uma das publicações da Comissão Trilateral, criada em $1973^{7}$ (GILL, 1990, p.138-9).

O termo interdependência seria central na obra mais conhecida da dupla Nye/Keohane: Power and Interdependence (1977), na qual os autores diziam rejeitar tanto o "realismo político", entendido como uma visão dominada pelo medo constante de conflitos militares, mas também se diferenciavam daqueles que eles consideravam serem "popularizadores da interdependência econômica", escritores que viam um eclipsamento quase total do Estado-nação por atores "não-territoriais" como corporações multinacionais e movimentos sociais transnacionais.

Posteriormente, Nye e Keohane enfatizariam que a interdependência complexa era menos uma teoria e mais um "tipo ideal" weberiano, isto é, uma construção abstrata com determinadas características. Na verdade, segundo os autores, tanto a "interdependência complexa" quanto o "realismo" teriam capacidades explicativas próprias de acordo com o tipo de situação em análise, sendo as relações do mundo real sempre localizadas em algum ponto entre o "modelo realista" e o "modelo da interdependência complexa". Enquanto as relações dentro do Oriente Médio, por
7. A Comissão Trilateral foi criada em 1973 por grandes empresários, políticos e intelectuais dos Estados Unidos, Europa Ocidental e Japão (os "três lados" representados nela em todas as suas reuniões e publicações). Os Trialogues são boletins trimestrais da Comissão Trilateral, reportando as principais questões norte-americanas, japonesas e européias. 
8. A "bargaining theory", muito influente entre os funcionalistas, definia uma "situação de barganha" como uma situação em que dois ou mais players têm um interesse comum em cooperar, mas têm conflitos de interesse sobre como cooperar exatamente (os players aqui podem ser tanto indivíduos, firmas, países ou organizações). 0 bargaining poderia definir qualquer processo, seja na arena política, econômica ou internacional, em que as partes envolvidas tentam chegar a um acordo (MUTHOO, 2000).

9. Os autores se defendem das críticas tanto de liberais como de realistas, de que sua análise de ambas tradições fossem incompletas em seu trabalho, afirmando que sua intenção não era mesmo desenvolver uma análise da história dessas tradições, e sim apenas examinar algumas pressuposições básicas de ambas no que concernia ao problema da interdependência (KEOHANE \& NYE, 1987, p. 729) exemplo, estariam mais próximas do "modelo realista", as relações entre EUA e Canadá estariam mais próximas da interdependência complexa (NYE, 2009, p.264-265).

Como definiu mais recentemente o próprio Nye,

"Como uma palavra analítica, interdependência refere-se a situações nas quais os protagonistas ou os acontecimentos em diferentes partes de um sistema afetam-se mutuamente. Simplificando, interdependência significa dependência mútua." (NYE, 2009, p.256)

Dessa maneira, admite-se que os Estados permanecem como os principais atores do sistema internacional, porém é levada em conta a "interação" destes com os "atores não-estatais" (corporações multinacionais, ONGs, e movimentos transnacionais diversos, como o ambientalismo). Nessa teoria, à segurança e a sobrevivência do Estado, que na teoria realista seriam os objetivos únicos do mesmo, são acrescidos outros interesses, como o "bem-estar econômico".

A análise de Nye e Keohane em Power and Interdependence continha basicamente três temas: uma análise política da política da interdependência, com base na teoria da negociação ${ }^{8}$; uma análise do tipo ideal que os autores chamaram de "interdependência complexa" e o impacto dos processos que ela abarcava; e uma tentativa de explicar as mudanças nos regimes internacionais - os quais eram definidos como "sets de arranjos governamentais que afetavam as relações de interdependência”.

O que os autores argumentavam, em Power and Interdependence, era que o uso da força se tornara crescentemente custoso para os Estados mais poderosos, como resultado de quatro condições: o risco de escalada nuclear; a "resistência do povo em países pobres ou mais fracos"; os "efeitos incertos e possivelmente negativos na realização dos objetivos econômicos"; e a "opinião doméstica se opondo aos custos humanos do uso da força”. Embora essas quatro condições tivessem impacto reduzido nas políticas de governos autoritários ou totalitários, assim como para grupos terroristas, o efeito líquido dessas tendências seria a "erosão da hierarquia baseada no poder militar". Neste ponto fica mais do que explícita a referência não apenas à vaga mobilizatória anti-guerra, como aos efeitos da mesma na própria estrutura militar dos Estados Unidos.

Escrevendo sobre Power and Interdependence dez anos depois, Nye e Keohane afirmaram que

\footnotetext{
"Nossa análise [de 1977] ligava as análises realistas e neo-realistas às preocupações dos liberais com a interdependência. Ao invés de ver a teoria realista como uma alternativa à 'teoria da interdependência' liberal, nós víamos ambas como complementares uma à outra. Essa abordagem era analiticamente justificada, em nossa visão, porque ambos, o realismo e o liberalismo, tinham suas raízes em uma visão utilitarista do mundo, na qual os atores individuais perseguem seus interesses próprios respondendo aos incentivos. Ambas as doutrinas vêem a política como um processo de troca política e econômica, caracterizada pela barganha. Falando de forma geral, tanto o realismo quanto o liberalismo são consistentes com a assunção de que a maior parte do comportamento estatal pode ser interpretada como atividade racional, ou ao menos inteligente. Realismo e liberalismo não são, pois, dois paradigmas incompatíveis, com concepções diferentes da natureza da ação política" (KEOHANE \& NYE, 1987, p.728-729). ${ }^{9}$
}

Segundo os próprios autores, o resultado de sua síntese analítica em Power and Interdependence teria sido "ampliar o neo-realismo e provê- 
-lo com novos conceitos" (KEOHANE \& NYE, 1987, p.733). Esse balanço é sintomático das inflexões ocorridas no próprio pensamento de Nye e principalmente de Keohane, a partir dos anos 1980.

A "revisita" ao clássico de 1977, da qual o trecho acima foi retirado, fora escrita em meio à era Reagan - a qual, para muitos observadores, foi marcada pelo uso da força e pela preocupação com a segurança, deixando para trás a "década da interdependência", que teriam sido os anos 1970. Isso não significou, entretanto, o abandono deste conceito, cujo desenvolvimento foi retomado por Nye nos anos 1990 e permanece em sua produção intelectual até o presente (NYE, 2005; NYE, 2009).

\section{Uma "interdependência" para desacreditar a "dependência"?}

Como vimos, a interdependência complexa, segundo Nye e Keohane, se referia a uma situação entre uma série de países nos quais múltiplos canais de contato conectam as sociedades (ou seja, os Estados não monopolizam esses contatos); em que não há uma hierarquia de questões, e a força militar não é utilizada pelos governos um contra o outro. A interdependência poderia trazer muitos benefícios, mas também acarretar altos custos, os quais poderiam se dar em termos de "sensibilidade" (grau do impacto que, em curto prazo, uma ocorrência num país projeta sobre os demais) ou de "vulnerabilidade" (que envolve os custos de mudar a estrutura de um dado sistema de interdependência).

Pois bem: neste raciocínio, as vantagens e desvantagens na relação de interdependência são classificadas em termos de "simetria" ou "assimetria", e nada teriam a ver, portanto, com considerar como interdependência apenas relações em que há "igual dependência". Assim, "manipular as assimetrias da interdependência pode ser uma fonte de poder na política internacional" (NYE, 2009, p. 256). Um tipo de interdependência poderia interferir em negociações que envolvem outro tipo, contrarrestando determinada "assimetria". Os autores, portanto, ligavam a interdependência à questão propriamente política apenas a partir do momento em que se considera que manipular uma "interdependência assimétrica" possui o potencial de constituir uma fonte de poder. ${ }^{10}$

Já em Transnational Relations and World Politics, de 1971, ficara explícito que a opção dos autores pelo termo "relação assimétrica de interdependência" tinha relação direta com sua rejeição total à idéia de imperialismo. Em suas palavras, o termo "imperialismo", além de "antigo", era por demais "ambíguo", podendo definir virtualmente "qualquer relação através das fronteiras nacionais entre desiguais que envolve o exercício da influência" - o que incluiria a maior parte da política mundial. Por isso, o conceito de imperialismo não teria qualquer valor heurístico, mesmo em um sentido mais restrito, quando referido, por exemplo, a uma relação na qual um poder desigual é usado para alcançar "alocações de valor injustas".

Nye e Keohane argumentavam que além de ser muito difícil concordar sobre o conceito de "justiça", "algumas relações transnacionais" seriam "imperialistas" e outras não, e portanto a ambigüidade do termo ainda estaria presente; sendo preferível, por isso, falar em "assimetrias"
10. Essa mesma idéia, segundo Nye e Keohane, começou a ser desenvolvida por HIRSCHMAN, 1945; e também podia ser encontrada na obra de Kenneth Waltz (KINDLEBERGER, 1970). 
ou, no máximo, em "desigualdades” (KEOHANE \& NYE, 1971, p.346). Ora, por este critério, também seria descartado o conceito de interdependência complexa. A questão é a rejeição não só ao termo imperialismo, mas também à própria idéia de dependência e a qualquer referência a uma relação estrutural de dominação entre países.

Enquanto o termo "imperialismo", "imperial" e outros similares refletem uma relação de dominação, o termo "assimetria" dá idéia de uma imperfeição, um desvio de padrão, que pode ser específico e conjuntural, nas relações entre países que estão essencialmente em pé de igualdade. A idéia de "interdependência" com "assimetrias" remete diretamente, ainda que não explicitamente, à noção de vantagens comparativas desenvolvida inicialmente por David Ricardo. Cada país exploraria, política e economicamente, seus diversos recursos, de maneira a maximizar seus ganhos no mercado e também na política internacional. No fundo, trata-se de uma visão benevolente do império.

Entretanto, como destaca um ensaio pioneiro de Franz Hinkelammert (1979), o conceito de interdependência não é estático, como na teoria econômica neoclássica, mas um conceito dinâmico, "de um processo com projeção futura", algo que chega a se elevar à condição de sujeito histórico, ainda que através de determinados homens. Existiria um processo histórico inexorável de avanço da interdependência (tal como seria apresentada a globalização nos anos 1990), mas também a necessidade de geri-la, pois ela, de acordo com seus autores, traria novos problemas à administração do sistema internacional - e administrar a nova situação significava conjugar o "máximo de interdependência com um mínimo de justiça social” (HINKELAMMERT, 1979, p.85). A colaboração de Nye e Keohane em projetos de "gestão da interdependência", no âmbito da Comissão Trilateral, seria uma evidência disso. E não seriam casuais as convergências de pensamento entre eles e outro importante teórico das Relações Internacionais do período, o "realista" Zbigniew Brzezinski, assunto que trataremos agora.

Congruências com Brzezinski

A idéia de interdependência e a rejeição à categoria de imperialismo ou de dependência esteve em muitos outros autores antes de Nye e Keohane. Em sua obra Entre duas Eras, de 1969, o sovietólogo de origem polonesa Z bigniew Brzezinski falava sobre como o poder econômico estaria se tornando cada vez mais despersonalizado, pelo surgimento de uma "interdependência de alta complexidade" entre instituições governamentais (inclusive a militar), os estabelecimentos científicos, e as indústrias (BRZEZINSKI, 1971 [1969]). Embora Brzezinski estivesse se referindo mais à relação entre instituições e esferas dentro de uma sociedade do que para as relações entre as sociedades, a coincidência dos termos é notável.

Mais uma vez retomando Hinkelammert, para o pensamento trilateralista, na nascente "era tecnetrônica" (termo cunhado por Brzezinski), os Estados não mais como portadores e defensores de interesses nacionais, mas sim como "lugares geográficos onde a interdependência acontece"; o que implicava, entre outras coisas, na renúncia a políticas nacionais 
como a de pleno emprego, surgidas como formato de contenção social e de desenvolvimento capitalista nas décadas do pós-Segunda Guerra (HINKELAMMERT, 1979, p.93).

Segundo Brzezinski, a influência da inovação e a presença econômica dos EUA, ou estimulada por ele, estaria preenchendo o lugar do "sistema imperial informal" consolidado pelos EUA especialmente ao fim da Segunda Guerra Mundial e início da Guerra Fria, período que conheceu a expansão de bases militares dos EUA pelo mundo todo (BRZEZINSKI, 1971, p.45). As análises marxistas do imperialismo, segundo Brzezinski, estariam erradas por "desconsiderar" esse novo tipo de relação com o mundo, já que veriam o imperialismo apenas como "expressão de um impulso imperial”, ignorando a dimensão da revolução científico-tecnológica que impeliria a imitação do país mais adiantado pelo mais atrasado, estimulando a exportação, dos primeiros para os segundos, de técnicas e habilidades de organização (BRZEZINSKI, 1971, p.45).

Nesse trecho, o sovietólogo omitia deliberadamente a obra de marxistas como V.I. Lênin (e dos marxistas lastreados na idéia de imperialismo como uma fase do capitalismo) ou L. Trotski, cuja teoria do desenvolvimento desigual e combinado, escrita ainda no início do século XX, procurara justamente entender os mecanismos através dos quais os países "atrasados" do ponto de vista do desenvolvimento capitalista "saltam etapas" e por isso mesmo adquirem feições políticas, sociais e econômicas peculiares (TROTSKY, 1967 [1932], p.23-32). Nota-se claramente a omissão ou apresentação caricatural do pensamento marxista.

Nas palavras de Brzezinski, poderia até haver "relações assimétricas" entre os países, mas o conteúdo dessa "assimetria" não poderia ser "tachado de imperialismo" (BRZEZINSKI, 1971, p.45). A coincidência dos termos usados por Brzezinski e por Nye e Keohane é digna de nota.

Embora as semelhanças entre as teorias de Brzezinski e de Nye e Keohane parem por aí, o fato é que as teses norteadoras dos trabalhos da já mencionada Comissão Trilateral ao longo da década de 1970 constituiriam uma síntese entre as duas matrizes de pensamento. Os eixos dessa síntese podem ser assim sistematizados: a) a noção de que havia um declínio na capacidade dos EUA de controlar o sistema internacional, juntamente com um aumento no poder econômico de outras potências, como Japão e Alemanha, tornando anacrônicas as linhas gerais da política dos anos Kissinger e exigindo a construção de uma "hegemonia compartilhada”; b) a percepção de que o Terceiro Mundo, na formação de alianças regionais e/ou de interesse específicos, como os exportadores de petróleo, poderia causar graves turbulências econômicas nos países centrais, havendo a necessidade de formar uma espécie de contra-coalizão, iniciando por uma coordenação entre os "países trilaterais"; e c) a ênfase na necessidade da criação e reforço das instituições internacionais, especialmente de instituições (pretensamente) "despolitizadas" e de caráter "técnico" (recomendações detalhadas e enfáticas presentes em diversos relatórios da comissão).

Os relatórios da Comissão Trilateral ao longo dos anos 1970 refletiriam tanto as teorias de Nye e Keohane quanto a de Brzezinski, três personagens que, ainda que com muitas desigualdades, tomaram parte ativa em 
11. Segundo Mendes Pereira, o relatório já recomendava mudanças no perfil das dívidas do Terceiro Mundo, com prazos maiores para vencimento, numa preocupação clara de manejar o desenfreado processo de endividamento externo de muitos desses países (MENDES PEREIRA, 2010, p.232).

12. Criado em 1921 e responsável pela prestigiada revista Foreign Affairs, 0 CFR é o mais tradicional think-tank de política externa nos Estados Unidos. sua elaboração. A Comissão Trilateral surge em 1973 a partir de um projeto desenvolvido no Council on Foreign Relations (CFR), com Brzezinski como principal organizador (GILL, 1990; SKLAR, 1980; MAIRA, 1982). Contava com a participação de políticos de partidos variados (dos "liberais" republicanos aos democratas, social-democratas alemães), empresários (em sua maioria esmagadora grandes corporações transnacionais de origem estadunidense, e em menor proporção japonesas, alemãs, inglesas, belgas e italianas), e também de dirigentes de importantes organismos internacionais, como Robert McNamara, então presidente do Banco Mundial. É interessante notar que o termo "interdependência" também tornou-se central no Relatório sobre o Desenvolvimento Mundial (RDM) de 1978, o primeiro de uma série de relatórios que se tornariam a principal publicação do Banco Mundial - o que mostra como muito além de uma teoria, a "interdependência" tornava-se parte de um programa de ação política por parte de organizações multilaterais. ${ }^{11}$ Nesse sentido, torna-se incontornável analisar a atividade política de seus autores junto a organizações diversas, a qual autoriza caracterizá-los como "intelectuais orgânicos".

Intelectuais orgânicos e aparelhos privados de hegemonia

O relatório anual de 1974 do Council on Foreign Relations (CFR) $)^{12}$ descrevia um novo programa, intitulado 1980's Project, cujo objetivo seria "ajudar a transformar o sistema político e econômico" (...) "em processo de mudanças aceleradas desde o fim dos anos 1960" (...) "pelo impacto da competição dentro do mundo capitalista avançado, pela guerra no Vietnã" (...) "pelos processos revolucionários no Terceiro Mundo e pela crise do sistema monetário internacional” (SHOUP \& MINTER, 1977, p.254).

Àquela altura, o acadêmico Joseph Nye era diretor do Committee for Economic Developement (CED). Criado em 1942, o CED, tal como o CFR, era uma associação entre grandes empresários e scholars, constituído inicialmente a partir de uma iniciativa do Departamento de Comércio. Constituía, assim como o CFR, um aparelho privado de hegemonia (GRAMSCI, 2007; LIGUORI, 2017, 44-45) que visava "resgatar o homem de negócios de seu próprio neandertalismo intelectual", e ao mesmo tempo "trazer acadêmicos e teorias para uma associação livre com homens que tenham chegado por esforço próprio a posições de comando na indústria e nos negócios” (DREIFUSS, 1987, p.42). Esse tipo de organização privada permitia, nas palavras da historiadora Virgínia Fontes, a

\footnotetext{
"difusão cosmopolita de certos interesses, de certas formas de agir e certas maneiras de pensar muito mais ampla e extensa do que se estivessem atadas aos acordos políticos internacionais ou às legislações nacionais que incidiam sobre atividades diretamente econômicas, vigentes para a instalação de empresas" (FONTES, 2010, p.174-5, grifo no original)
}

Nos anos 1970, o CED, juntamente com seus counterparts internacionais, estava promovendo estudos e eventos acerca da crise do sistema monetário internacional e das relações entre as corporações transnacionais e o Terceiro Mundo (DREIFUSS, 1987, p.80). Logo, compreende-se o convite a Nye para que ele se somasse ao seleto Coordinating Group do 1980's Project do CFR. 
O Coordinating Group do 1980's Project foi composto majoritariamente por professores universitários, entre eles os economistas Richard N. Cooper e Carlos Diaz-Alejandro, de Yale; os professores de Harvard Stanley H. Hoffman e Samuel Huntington; Richard Falk, de Princeton; o professor de estudos ambientais Gordon J. MacDonald, de Dartmouth, e os professores de ciência política da Universidade de Michigan Ali Mazrui e Alan S. Whiting. ${ }^{13}$ Mas contava também com três membros do mundo corporativo: $\mathrm{W}$. Michael Blumenthal, diretor da Bendix; Stephen Stamas, vice-presidente da Exxon; e Edwin K. Hamilton, presidente da Griffenhagen-Kroeger Inc; e Bruce K. MacLaury, presidente do Federal Reserve Bank, Minneapolis.

O grupo coordenador do 1980's Project tinha três futuros membros da Comissão Trilateral: Richard Cooper, Bruce K. MacLaury e o próprio Joseph Nye. Além deles, oito diretores do CFR entraram para a Trilateral logo de sua criação, entre eles Brzezinski, Gerard Smith, George Franklin e David Rockefeller, então presidente do Chase Manhattan Bank e de ativo engajamento político-diplomático, responsável por grande parte dos fundos levantados para a criação da entidade (ROCKEFELLER, 2002, p.444-447).

A primeira publicação do 1980's Project, assinada pela economista Miriam Camps, levou o sugestivo título de The management of Interdependence: a preliminary view. O livro/relatório foi concluído após dois anos de encontros do grupo de estudos sobre o tema no âmbito do 1980's Project, entre 1971 e 1973 (CAMPS, 1974). Nele, afirmava-se que nenhuma nação poderia mais jogar o papel que os EUA jogaram no passado, e que, diante disso, seria imprescindível uma "administração coletiva" por parte dos poderes industriais capitalistas avançados (SHOUP \& MINTER, 1977, p.265-7).

A participação mais ativa de Nye e Keohane nos trabalhos da Comissão Trilateral se deu nos seus task-force reports (TFRs) voltados ao tema das instituições internacionais, que ocuparia parte significativa dos esforços da Comissão Trilateral entre 1976 e 1978, com três densos relatórios elaborados com a consultoria de Nye, Keohane e diversos outros intelectuais acadêmicos dos Estados Unidos, da Europa Ocidental e do Japão.

No décimo primeiro Task-Force Report (TFR) da comissão, intitulado "A reforma das instituições internacionais", assinado por C. Fred Bergsten, Georges Berthoin e Kinhide Mushakoji, escrito em 1976 com a consultoria de Robert Keohane, o termo interdependência é central, embasando propostas de reformas das organizações multilaterais como a ONU (BERGSTEN, BERTHOIN, MUSHAKOJI, 1976). ${ }^{14}$ A proposta era, essencialmente, retirar poder deliberativo da ONU, considerada uma organização muito "política", e transferi-lo a organismos mais "técnicos" e descentralizados, onde os "acordos mais efetivos" poderiam ser fechados.

O termo "interdependência complexa" apareceria fartamente em outro TFR da comissão, intitulado "Em direção a um sistema internacional renovado", escrito por Richard Cooper, Karl Kaiser e Masataka Kosaka, que recebeu consultoria de 22 comissionários, entre eles Joseph Nye (COOPER et all, 1977) ${ }^{15}$. É neste último documento onde se pode encontrar o simbólico trecho em epígrafe ao presente artigo, uma das raras menções diretas à teoria da dependência:
13. Whiting e MacDonald eram consultores do Departamento de Estado, e o último do Departamento de Defesa. Huntington era editor da recém fundada Foreign Policy, em cujo conselho editorial Falk, Cooper, Nye e Hoffman participavam (SHOUP \& MINTER, 1977, p. 257-258).

14. 0 relatório encontra-se disponível em: http://trilateral.org/file/11. Acessado em 17 de outubro de 2017.

15. Relatório disponível em http://trilateral.org/file/14. Acessado em 17 de outubro de 2017. 
16. Criado em 2007, o CNAS, conforme sua própria descrição, lida com "questões de segurança nacional" como "terrorismo e guerra irregular", com "0 futuro das Forças Armadas dos EUA", "as implicações para a segurança nacional do consumo de recursos naturais", entre outros temas. Ver CNAS - Who we are - Mission: https://www.cnas. org/mission (acessado em 30 de maio de 2017) "para os países em desenvolvimento mais fracos, a interdependência aparece como um sistema de dependência. Daí o apelo de teorias que enfatizam elementos de dependência na economia mundial, incluindo as corporações multinacionais, e as quais formam a base para grande parte da retórica, senão da estratégia política, de muitos países em desenvolvimento" (COOPER et all, 1977, p.191, grifo nosso)

O relatório, escrito, conforme seus próprios autores, com a colaboração de Joseph Nye, era um verdadeiro deboche das idéias defendidas pelos teóricos da dependência, caracterizando-as como um "atrasado nacionalismo econômico", como uma forma de "protecionismo" que deveria ser abolida em prol das boas relações entre os países, como a defesa de interesses egoístas responsável pelo acirramento dos conflitos internacionais, ao invés de resolvê-los. Tratava-se de desenvolver uma sofisticada estratégia de combate às políticas anti-imperialistas, informadas ou não pelas teorias dependentistas, e para isso a teoria da interdependência servia como uma luva.

Desta forma, podemos afirmar que as teses desenvolvidas por Nye e Keohane não estavam de nenhum modo desligadas das formas de organização de classe na sociedade civil - que podemos entender, a partir de Antonio Gramsci, como aparelhos privados de hegemonia. Ao contrário, estiveram intimamente ligadas a determinadas políticas defendidas por determinadas frações de classe organizadas nesses aparelhos - no caso da Trilateral, especificamente do capital monopolista que constituía as corporações transnacionais originárias dos países imperialistas centrais. Por esse motivo podemos, novamente com Gramsci, entendê-los como intelectuais orgânicos (GRAMSCI, 2007; VOZA, 2017, p.430-431).

A trajetória posterior de Nye seria marcada por alguma atuação no próprio seio da sociedade política (Estado strictu sensu) nos Estados Unidos, com mais destaque em administrações democratas. Entre 1977 e 1979, durante o mandato de Carter, ele serviu na Subsecretaria de Estado para Assistência à Segurança, Ciência e Tecnologia, e presidiu o Grupo do Conselho Nacional de Segurança para a não-proliferação de armas nucleares, função pela qual receberia o prêmio de Distinguished Honor do Departamento de Estado em 1979.

Em 1993 e 1994, já na administração Clinton, Nye seria indicado diretor no influente National Intelligence Council, órgão que se reportava diretamente ao Presidente; e em 1994 tornaria-se Secretário Assistente de Defesa para Questões de Segurança Internacional, recebendo prêmios estatais por sua atuação ambos os cargos. Em outubro de 2014, foi indicado pelo Secretário de Estado da administração Obama, John Kerry, para o Foreign Affairs Policy Board, grupo que se reunia periodicamente para discutir questões estratégicas e que reportava-se diretamente ao Secretário de Estado.

Além dos cargos estatais, Nye faria parte de uma série de organizações privadas e instituições de pesquisa intimamente ligadas ao Estado strictu sensu, entre eles think tanks prestadoras de serviços de "consultoria”. Exemplos disso são o Project on National Security Reform (PNSR), criado em 2006, que, formalmente "estuda formas de reorganizar a estrutura estatal de segurança nacional" diante do advento das "novas ameaças" como "terrorismo", "crime transnacional", etc, e o Center for a New American Security (CNAS), criado em $2007 .{ }^{16}$ Seus trabalhos na Comissão Tri- 
lateral prosseguiram de forma ininterrupta, e desde 2008 Nye é o diretor norte-americano da entidade. ${ }^{17}$

Diferindo neste ponto de Nye, Keohane não chegou a ocupar cargos significativos na sociedade política - o que certamente não significou distância dos círculos de poder ou isenção em relação a políticas do Estado.

Considerações finais

No início dos anos 1970, a teoria da dependência ultrapassava o debate intelectual latino-americano, onde já tinha proeminência, e irradiava-se para centros de pensamento americanos e europeus, confluindo com o rico debate marxista que ali também se desenvolvia como parte da renovação da teoria do imperialismo, constituindo um desafio político e teórico que foi enfrentado por intelectuais como Brzezinski, Nye e Keohane.

Como procuramos demonstrar, a teoria da interdependência constituiu um arcabouço conceitual que informou estratégias políticas privadas e estatais, impulsionadas por frações dominantes das classes dominantes nos países imperialistas centrais. Discutida e incorporada em aparelhos privados de hegemonia como o Council on Foreign Relations (CFR), o Committee for Economic Development (CED) e a Comissão Trilateral, a teoria da interdependência embasou propostas, por parte dessas entidades, de reformas das instituições internacionais, de política monetária, política externa, política de "assistência econômica" internacional, entre muitas outras. Tal arcabouço entrava em choque com a teoria da dependência, que em suas distintas variantes, reconhecia o imperialismo e a dominação econômica e política no plano internacional como um determinante fundamental das relações internacionais.

Tendo reconhecimento inegável na disciplina de R.I. desde então, a teoria da interdependência é infinitamente mais conhecida na área do que as teorias da dependência. Trazer as últimas de volta ao debate e identificar todos os autores em suas posições políticas é fundamental para que os estudantes de Relações Internacionais tenham acesso ao tipo de contraposição teórica que lhes foi durante tanto tempo negada.

Referências

AHMAD, Aijaz. Linhagens do presente. Ensaios. São Paulo: Boitempo, 2002.

ALI, Tariq. O poder das barricadas. São Paulo: Boitempo, 2005.

ASSMAN, Hugo; SANTOS, Theotônio dos; CHOMSKY, Noam (orgs.). A Trilateral - nova fase do capitalismo mundial. Petrópolis: Vozes, 1979.

BERSGTEN, C. Fred. "The new era in the world commodity markets". Challenge, set/out 1974. BLOCK, Fred. The origins of International Economic Disorder. A study of United States International Monetary Policy from World War II to the present. Berkley/Los Angeles: University of California Press, 1977.

BERGSTEN, C. Fred; BERTHOIN, Georges \& MUSHAKOJI, Kinhide. The reform of international institutions. Trilateral Commission: Task-Force Report n.11, 1976.

BRZEZINSKI, Zbigniew. Entre duas eras. América: laboratório do mundo. Rio de Janeiro: Artenova, 1971 [1969].

CAMPS, Miriam. The Management of Interdependence: a preliminary view. New York: Council on Foreign Relations, 1974.
17. Ver Trilateral Commission - "Leadership". Disponível em: http://trilateral. org/page/10/north-american-group. Acessado em 29 de maio de 2017 
CARDOSO, Fernando Henrique \& FALETTO, Enzo. Dependência e desenvolvimento na América Latina: ensaio de interpretação sociológica. Rio de Janeiro: Zahar, 1977 [1967].

COOPER, Richard N. The economics of interdependence: economic policy in the Atlantic Community. New York: McGraw-Hill Book Co, 1968

COOPER, Richard; KAISER, Karl \& KOSAKA, Masataka. Towards a renovated international system Trilateral Commission: Task-Force Report n.14, 1977.

CORREA, Hugo Figueira de Souza. Teorias do imperialismo no século XXI: (in) adequações do debate no marxismo. Tese de doutorado em Economia. Universidade Federal Fluminense, 2012.

DREIFUSS, René Armand. A internacional capitalista. Estratégias e táticas do empresariado transnacional (1918-1986). $2^{\text {a }}$ edição. Rio de Janeiro: Espaço e Tempo, 1987.

FONTES, Virgínia. O Brasil e o capital-imperialismo. Teoria e História. Rio de Janeiro: EPSJV/UFRJ, 2010

FOSTER, John Bellamy. “The Rediscovery of imperialism”. Monthly Review, vol.54, Nov.2002.

FURTADO, Celso. Desenvolvimento e subdesenvolvimento. Rio de Janeiro: Fundo de Cultura, 1961.

GILL, Stephen. American Hegemony and the Trilateral Commission. Cambridge: Cambridge University Press, 1990.

GRAMSCI, Antonio. Cadernos do Cárcere. Volumes 3, 4 e 5. Rio de Janeiro: Civilização Brasileira, 2007.

GREEN, James. Apesar de vocês. Oposição à ditadura brasileira nos Estados Unidos, 1964-1985. São Paulo: Companhia das Letras, 2009.

GUNDER FRANK, Andre. “The development of underdevelopment”. Monthly Review, vol. 18, n.4, setembro de 1966 .

GURRIERI, Adolfo. La obra de Prebisch en la Cepal. México: Fondo de Cultura Económica, 1982.

HERZ, Monica. “Teoria das Relações Internacionais no Pós-Guerra Fria”. Dados, Rio de Janeiro, vol.40, n.2, Janeiro de 1997.

HINKELAMMERT, Franz. "O credo econômico da Comissão Trilateral”. In ASSMAN, Hugo; SANTOS, Theotônio dos; CHOMSKY, Noam (orgs.). A Trilateral - nova fase do capitalismo mundial. Petrópolis: Vozes, 1979.

HIRSCHMAN, Albert. National Power and the Structure of Foreign Trade. Berkeley: University of California Press, 1945.

JAMESON, Fredric. "Periodizando os anos 60". In. HOLLANDA, Heloísa Buarque de (org.). Pós-modernismo e política. Rio de Janeiro: Rocco, 1992.

KEOHANE, Robert. “The Big Influence of Small Allies,” Foreign Policy, no. 2, primavera de 1971.

KEOHANE, Robert. "Institutionalization in the United Nations General Assembly," International Organization, vol. 23, no. 4, outono de 1969.

KEOHANE, Robert. "The Study of Political Influence in the General Assembly," International Organization, vol. 21, no. 2, primavera de 1967.

KEOHANE, R. \& NYE, Joseph S. Transnational Relations and World Politics: an introduction. International Organization, vol.25, n.3. p.329-349, verão de 1971.

KEOHANE, Robert O. \& NYE, Joseph. Transnational Relations and World Politics, Cambridge, Massachussets: Harvard University Press, 1972.

KEOHANE, Robert \& NYE, Joseph. Power and Interdependence: world politics in transition. Boston: Little, Brown and Company, 1977.

KEOHANE, Robert \& NYE, Joseph. “Power and Interdependence revisited”. International Organization, vol. 41, n.4, p.725-753, Outono de 1987.

KEOHANE, Robert \& NYE, Joseph. "Power and Interdependence in the Information Age”. Foreign Affairs, set/out de 1998.

LENS, Sidney. A fabricação do império americano. Da revolução ao Vietnã: uma história do imperialismo dos Estados Unidos. Rio de Janeiro: Civilização Brasileira, 2006 [1971].

LEWIS, W. Arthur. The theory of economic growth. Londres: G. Allen \& Unwin, 1955.

LIGUORI, Guido. Aparelho hegemônico (Verbete). In. LIGUORI, Guido \& VOZA, Pasquale (orgs). Dicionário Gramsciano (1926-1937). São Paulo: Boitempo, 2017, p.44-45. 
LUCE, Mathias Seibel. A teoria do subimperialismo em Ruy Mauro Marini: contradições do capitalismo dependente e a questão do padrão de reprodução do capital: a história de uma categoria. Tese de doutorado. Universidade Federal do Rio Grande do Sul, 2011.

MAGDOFF, Harry. A Era do Imperialismo. São Paulo: Hucitec, 1978 [1969].

MAIRA, Luis. America Latina y La crisis de hegemonia norte-americana. Lima, Peru: Desco/ Centro de Estudios y promocion del desarollo, 1982.

MARINI, Ruy Mauro. América Latina: Dependência e integração. São Paulo: Editora Página Aberta, 1992.

MARINI, Ruy Mauro. "A acumulação capitalista mundial e o subimperialismo". In. Outubro, São Paulo, n.20, p.32-70, 2012 [1977].

MARINI, Ruy Mauro. "Dialética da dependência” [1973]. In SADER, E. (Org.). Dialética da dependência: uma antologia da obra de Ruy Mauro Marini. Petrópolis: Vozes, 2000.

MARINI, Ruy Mauro. Subdesenvolvimento e revolução. Florianópolis: Insular, 2012.

MARX, K. O Capital: crítica da economia política. 5 volumes, Abril Cultural, São Paulo, 1984.

MARX, Karl \& ENGELS, Friedrich. "Manifesto do Partido Comunista" [1848]. In. COUTINHO, Carlos Nelson (org.) et all, O Manifesto Comunista - 150 anos depois. Rio de Janeiro: Contraponto/São Paulo: Perseu Abramo, 1998.

MENDES PEREIRA, João Márcio. O Banco Mundial como ator político intelectual e financeiro (1944-2008). Rio de Janeiro: Civilização Brasileira, 2010.

MUTHOO, Abhinay. "A non-technical introduction to bargaining theory". World Economics, vol. 1, n.2, abril-junho de 2000.

NOGUEIRA, João Pontes \& MESSARI, Nizar. Teoria das Relações Internacionais: correntes e debates. Rio de Janeiro: Elsevier, 2005.

NYE, Joseph S. Pan africanism and East African integration. Cambridge: Harvard University Press, 1965.

NYE, Joseph S. "Central American Regional Integration”. In. International Conciliation, Março de 1967.

NYE, Joseph S. “A Latin Example for African Regionalists,” Africa Report, April 1968.

NYE, Joseph S. "Comparing Common Markets: A Revised Neo-Functionalist Model," International Organization, outono de 1970.

NYE, Joseph S. Peace in Parts: Integration and Conflict in Regional Organization. Boston: Little Brown and Company, 1971.

NYE, Joseph S.; HAAS, Ernst B. \& BUTTERWORTH, Robert (eds.). Conflict Management by International Organizations. New Jersey: General Learning Press, 1972.

NYE, Joseph S. O paradoxo do poder americano. Por que é que a única superpotência mundial não pode actuar isoladamente. Lisboa: Gradiva, 2005 [2002].

NYE, Joseph S. Cooperação e conflito nas Relações Internacionais. Uma leitura essencial para entender as principais questões da política mundial. São Paulo: Editora Gente, 2009.

ROCKFELLER, David. Memórias. Rio de Janeiro: Rocco, 2002.

SHOUP, Laurence H. \& MINTER, William. Imperial Brain Trust. The Council fo Foreign Relations and the United States Foreign Policy. Monthly Review Press, 1977.

SKLAR, Holly (org.). Trilateralism: managing dependence and democracy. Boston: South and Press, 1980.

TROTSKY, Leon. A história da revolução russa. Rio de Janeiro: Saga, 1967 [1932].

VALENCIA, Adrián Sotelo. La teoría de la dependência em el siglo XXI. Cidade do México: Plaza y Valdés, 2005.

VOZA, Pasquele. Intelectuais orgânicos (Verbete). In. LIGUORI, Guido \& VOZA, Pasquale (orgs). Dicionário Gramsciano (1926-1937). São Paulo: Boitempo, 2017, p.430-431.

WALTZ, Kenneth. "The myth of National Interdependence". In KINDLEBERGER, Charles (ed.) The international Corporation. Cambridge: MIT Press, 1970. 